\title{
THE COMPARATIVE OVERVIEW OF HPLC ANALYSIS OF DIFFERENT EXTRACTS FROM MORUS SPECIES FROM SOUTHEAST SERBIA
}

\author{
DANICA DIMITRIJEVIĆa*, DANIJELA KOSTIĆb, MILAN MITIĆb, \\ DUŠAN PAUNOVIĆa, BRANKA STOJANOVIĆa, JOVANA KRSTIĆa, \\ SLAVICA STEVANOVIĆa , JASMINA VELIČKOVIĆ ${ }^{a}$
}

\begin{abstract}
The aim of this work was to evaluate the content of phenolic compounds (phenols, flavonoids and anthocyanins) of Morus alba L. fruit (white mulberry), Morus rubra L. (red mulberry) and Morus nigra L. fruit (black mulberry) by the HPLC analysis. In the extracts of white, red and black mulberry identified the four phenolic acids by HPLC analysis: chlorogenic, 4-caffeoylquinic, 5caffeoylquinic and caffeic acid. 5-caffeoylquinic acid was identified in all tested extracts of white, red and black mulberry. 4-caffeoylquinic acids contain all the extracts except methanol extract of red mulberry. Caffeic and chlorogenic acid containing methanol extracts of white and red mulberry.
\end{abstract}

Keywords: Morus species, HPLC analysis.

\section{INTRODUCTION}

The mulberry belongs to the genus Morus of the family Moraceae. Mulberry is found from temperate to sub-tropical regions of the Northern hemisphere to the tropics of the Southern hemisphere and they can grow in a wide range of climatic, topographical and soil conditions. These are widely spread throughout all regions from the tropics to the sub-arctic areas. Genus Morus is widespread in Asia, Europe, North and South America and Africa as well.

Morus species are deciduous and in a period of low temperatures during the winter require to break dormancy. Mulberry fruit may be colored white, red or black when they are ripe. Deep-colored fruits are good sources of phenolics, including flavonoids, anthocyanins and carotenoids [1-4], and

\footnotetext{
a Faculty of Applied Sciences, University of Belgrade, Serbia

b Faculty of Sciences and Mathematics, University of Nis, Serbia

${ }^{*}$ Corresponding author: danicadimitrijevic7@gmail.com
} 
mulberries are rich in phenolics [5]. Mulberry has an unique delicious fruit, sour and refreshing taste. It has been used as a folk remedy to treat oral and dental diseases, diabetes, hypertension, arthritis and anemia [6]. The bright black and purple mulberry fruits, which have a very pleasant taste when eaten fresh, are also used in jams, juices, liquors, natural dyes as well as in the cosmetics industry [7]. The plant has high level of anthocyanins; hence it has a very important role in the food industry. It is considered that the fresh fruit color comes from anthocyanins present in the fruit. This has contributed to the positive effects of fruit on the people health. The mulberry is found to be especially rich in anthocyanins, flavonoid and phenol compounds. The total content and the yield (percentage) of these compounds is dependent on geographic location and soil on which the mulberry tree grows. Despite the previous research on this plant, there is no information about its contents. Accordingly, the results obtained in this study differ from the results of Morus species found in other countries.

\section{RESULTS AND DISCUSSION}

Table 1 shows a comparative overview of HPLC analysis of three types of mulberry.

A total of four phenolic acids have been identified in white, red and black mulberry extracts: chlorogenic, neochlorogenic, cryptochlorogenic and caffeic acid. Neochlorogenic acid was confirmed in both methanolic and acetone extracts of white, red and black mulberry. Cryptochlorogenic acid contains all extracts except methanolic red mulberry extract. Caffeine and chlorogenic acid contain methanolic extracts of white and red mulberry. The lowest content was found of caffeic acid in methanolic extract of white mulberry $(3.80 \mathrm{mg} / \mathrm{kg})$, while the highest amount of neochlorogenic acid in methanolic extract of black mulberry fruit $(231.41 \mathrm{mg} / \mathrm{kg})$.

HPLC analysis confirmed the presence of the following flavonoids in the tested extracts: quercetin-3-O-rutinoside, quercetin-3-O-glucoside, quercetin-3-O-rhamnoside, kaempferol-3-O-rutinoside and quercetin. All tested extracts of the three types of mulberry contain quercetin-3-O-rutinoside and quercetin-3-O-glucoside. Quercetin-3- O-rhamnoside contains all tested extracts except methanolic extracts of white and red mulberry. Kaempferol-3O-rutinoside contains methanolic white and red mulberry extracts and acetone white mulberry extract. Quercetin contains only methanolic extract of black mulberry. The lowest amount of quercetin-3-O-glucoside $(5.02 \mathrm{mg} / \mathrm{kg})$ was recorded in acetone extract of white mulberry, while the highest amount of quercetin-3-O-rutinoside was recorded in methanolic extract of black mulberry (123.17 mg / kg). 

MORUS SPECIES FROM SOUTHEAST SERBIA

Table 1. A comparative overview of HPLC analysis of three types of mulberry

\begin{tabular}{|l|r|r|r|r|r|r|}
\hline \multicolumn{1}{|c|}{$\begin{array}{c}\text { Phenolic acid mg/kg } \\
(320 \mathrm{~nm})\end{array}$} & \multicolumn{1}{c|}{ Black mulberry } & \multicolumn{2}{c|}{ Red mulberry } & \multicolumn{2}{c|}{ White mulberry } \\
\cline { 2 - 8 } & methanol & acetone & methanol & acetone & Methanol & acetone \\
\hline Chlorogenic acid & - & - & 9.22 & - & 7.36 & - \\
\hline Caffeic acid & - & - & 3.87 & - & 3.80 & - \\
\hline Neochlorogenic acid & 231.41 & 22.29 & 6.76 & 15.18 & 25.21 & 22.99 \\
\hline Criptochlorogenic acid & 143.28 & 18.34 & - & 8.57 & 24.15 & 8.92 \\
\hline Flavonoids (360nm) & & & & & & \\
\hline Quercetin-3-O-rutinoside & 123.17 & 29.12 & 12.59 & 13.94 & 16.91 & 26.58 \\
\hline Quercetin-3-O-glucoside & 64.88 & 18.96 & 6.10 & 5.78 & 26.04 & 5.02 \\
\hline Quercetin-3-O-ramnoside & 38.89 & 44.62 & - & 22.85 & - & 24.91 \\
\hline Kaempherol-3-O-rutinoside & - & - & 18.52 & - & 8.12 & 5.13 \\
\hline Quercetin & 4.21 & - & - & - & - & - \\
\hline Anthocians (520nm) & & & & & & \\
\hline Cyanidine-3-O-glucoside & 888.32 & 32.72 & 11.17 & - & - & - \\
\hline Cyanidine-3-O-rutinoside & 349.94 & 5.36 & - & - & - & - \\
\hline Pelargonidine-3-O-glucoside & 12.19 & 1.73 & - & - & - & - \\
\hline Pelargonidine-3-O-rutinoside & 2.98 & - & - & - & - & - \\
\hline
\end{tabular}

Qualified and quantified anthocyanins in the extracts of the three types of mulberry are: cyanidin-3-O-glucoside, cyanidin-3-O-rutinoside, pelargonidin3-O-glucoside, and pelargonidin-3-O-rutinoside. Cyanidin-3-O-glucoside contains the methanolic and acetone extracts of red and black mulberry. Cyanidin-3O-rutinoside and pelargonidin-3-O-glucoside contain only methanolic and acetone extracts of black mulberry fruit. Pelargonidine-3-O-rutinoside is only present in methanolic extract of black mulberry fruit. White mulberry does not contain anthocyanins.

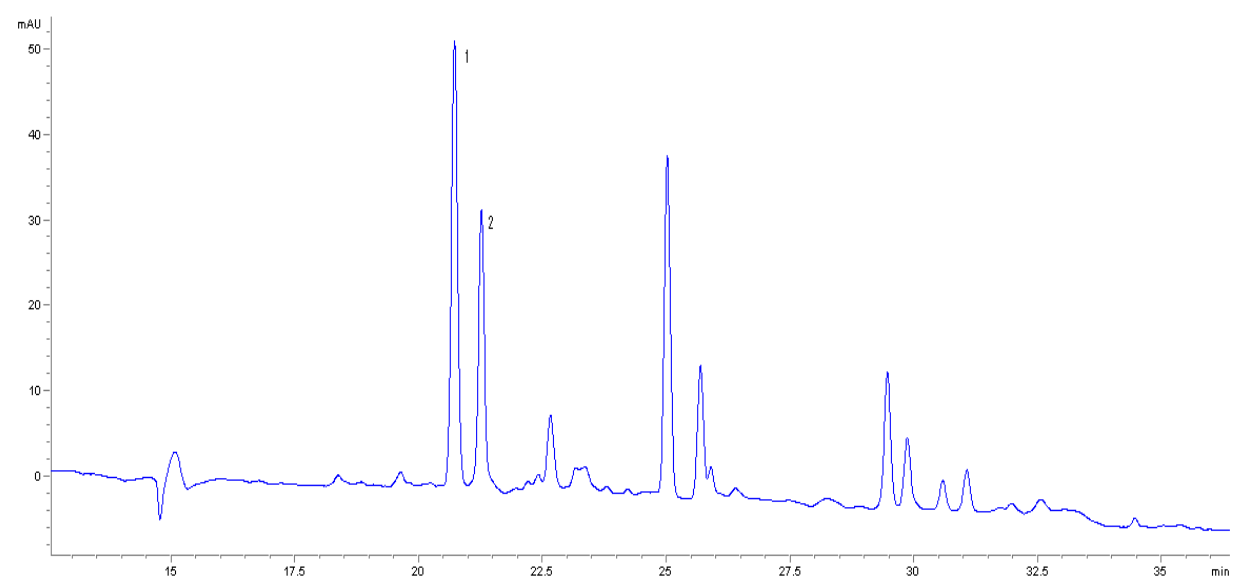

Figure 1. HPLC analysis of acetone extract of black mulberry (Morus nigra L.) at $320 \mathrm{~nm}$ : neochlorogenic acid (1), cryptochlorogenic acid (2). 
DANICA DIMITRIJEVIĆ, DANIJELA KOSTIĆ, MILAN MITIĆ, DUŠAN PAUNOVIĆ, BRANKA

STOJANOVIĆ, JOVANA KRSTIĆ, SLAVICA STEVANOVIĆ, JASMINA VELIČKOVIĆ

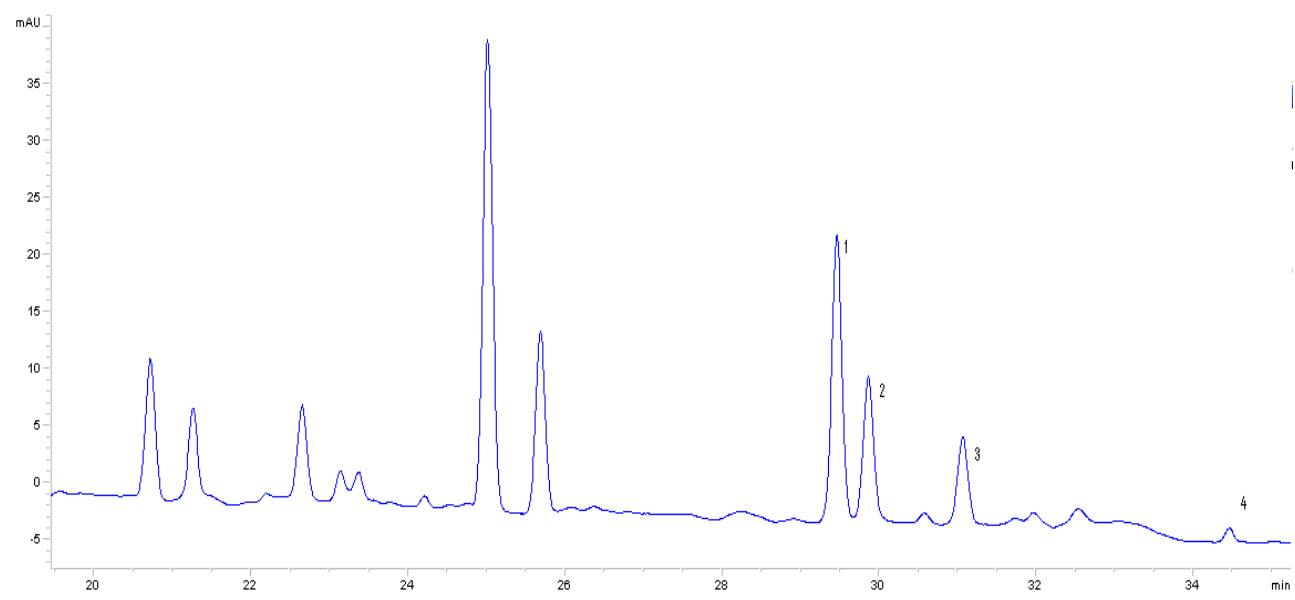

Figure 2. HPLC analysis of acetone extract of black mulberry fruit (Morus nigra L.) at $360 \mathrm{~nm}$ : quercetin-3-O-rutinoside (1), quercetin-3-O-glucoside (2), quercetin-3-O-rhamnoside (3), quercetin (4).

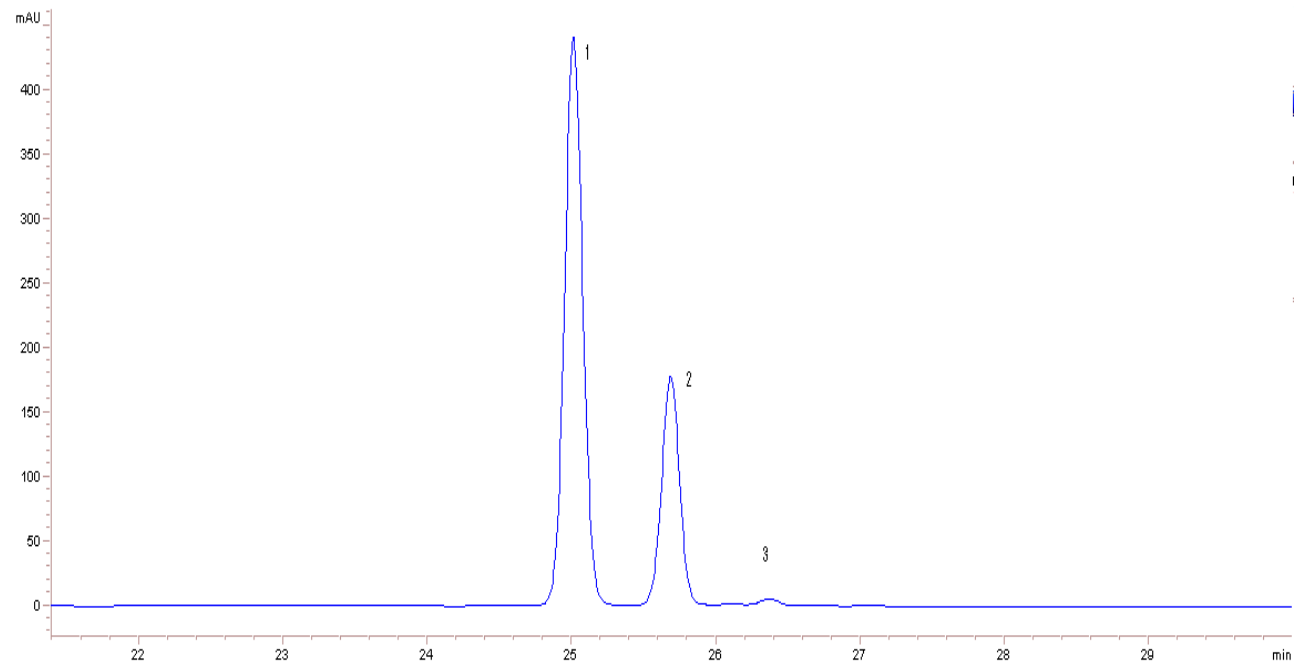

Figure 3. HPLC analysis of acetone extract of black mulberry fruit (Morus nigra L.) at $520 \mathrm{~nm}$ : cyanidin-3-O-glucoside (1), cyanidin-3-O-rutinoside (2), pelargonidin-3-O-glucoside.

Phenolic compounds isolated from different parts of the mulberry (fruit, leaf, root, tree) and then identified by HPLC analysis are shown in Table 2. 

MORUS SPECIES FROM SOUTHEAST SERBIA

Table 2. Compounds isolated from mulberry (fruit, leaf, root, tree) by HPLC analysis

\begin{tabular}{|c|c|c|c|c|}
\hline Compound & Morus Nigra L. & Morus rubra $L$. & Morus alba $L$. & Ref. \\
\hline Cyanidin- 3-O- $\beta$-D-glucopiranoside & - & - & + & [8] \\
\hline Cyanidin-3-O- $\beta$-D-galactopiranoside & - & - & + & [8] \\
\hline Cyanidin- 7-O- $\beta$-D-glucopiranoside & - & - & + & [8] \\
\hline \multirow{3}{*}{ Cyanidin-3-O-glucoside } & + & - & - & [9] \\
\hline & + & - & + & [10] \\
\hline & + & - & - & [11] \\
\hline Quercetin-3-O-ramnosid-7-O-glucoside & - & + & + & [12] \\
\hline $\begin{array}{l}\text { Quercetin-3,7-di-O- } \beta \text {-D- } \\
\text { glucopiranoside }\end{array}$ & - & + & + & [12] \\
\hline Kaempferol-7-O-glucoside & - & + & + & [12] \\
\hline Kaempferol-3-O-rutinoside & + & - & + & [10] \\
\hline Kaempferol & - & - & + & [13] \\
\hline \multirow{5}{*}{ Rutin } & + & + & + & [14] \\
\hline & - & - & + & [13] \\
\hline & + & + & + & [12] \\
\hline & + & + & + & [15] \\
\hline & + & - & + & [16] \\
\hline \multirow{4}{*}{ Quercetin } & + & + & + & [14] \\
\hline & + & - & + & [16] \\
\hline & - & - & + & [13] \\
\hline & + & + & + & [15] \\
\hline Catechine & + & + & + & [14] \\
\hline Quercetin-3-O-glucoside & + & + & + & [12] \\
\hline Quercetin-3-O-rutinoside & + & - & - & [9] \\
\hline Taxifolin & + & - & - & [17] \\
\hline \multirow{4}{*}{ Chlorogenic acid } & + & - & + & [7] \\
\hline & + & + & + & [14] \\
\hline & - & - & + & {$[13]$} \\
\hline & + & - & + & {$[16]$} \\
\hline \multirow{2}{*}{ p-coumaric acid } & + & + & + & [14] \\
\hline & + & - & + & [7] \\
\hline \multirow{2}{*}{ m-coumaric acid } & + & - & + & [14] \\
\hline & + & - & + & [7] \\
\hline o-coumaric acid & + & + & + & [14] \\
\hline \multirow{2}{*}{ Vanillic acid } & + & + & + & [14] \\
\hline & + & - & + & [7] \\
\hline \multirow{4}{*}{ Gallic acid } & + & - & + & [16] \\
\hline & + & + & + & [14] \\
\hline & - & - & + & [13] \\
\hline & + & - & + & [7] \\
\hline \multirow{3}{*}{ Caffeic acid } & - & - & + & [13] \\
\hline & + & + & + & [14] \\
\hline & - & + & + & [12] \\
\hline \multirow{2}{*}{ Ferullic acid } & + & - & + & [13] \\
\hline & + & - & + & [16] \\
\hline Criptochlorogenic acid & - & + & + & [12] \\
\hline Neochlorogenic acid & - & + & + & [12] \\
\hline
\end{tabular}


The following compounds were isolated from a white mulberry picked in China: cyanidin-3-O- $\beta$-D-glucopyranoside, cyanidin-3-O- $\beta-D-$ galactopyranoside and cyanidin-7-O- $\beta$-D-glucopyranoside [8]. Cyanidin-3-glucoside and quercetin3-O-rutinoside were isolated from a black mulberry harvested in Spain [9], whereas by HPLC-PDAESI-MS analysis of a black and white mulberry from Poland isolated cyanidin-3-glucoside and kaempferol-3-O-rutinoside [10].

Tunisia red and white mulberry were analyzed by injecting a solution of known concentration of chlorogenic acid $(250 \mu \mathrm{g} / \mathrm{ml})$, caffeic acid $(100 \mu \mathrm{g} / \mathrm{ml})$, routine $(235 \mu \mathrm{g} / \mathrm{ml})$ and quercetin $(200 \mu \mathrm{g} / \mathrm{ml})$ [12]. Chlorogenic and caffeic acid were selected because they had already been identified with their derivatives in red and white mulberry extracts. Rutine was used as an equivalent for the quantification of quercetin and kaempferol-diglycoside. Caempferol derivatives differ from quercetin derivatives only by the position of the hydroxyl group at the 3 'position of the flavan ring. Quercetin was used as the standard to quantify the monoglycoside derivatives of quercetin and kaempferol [12].

The HPLC method, as the primary analytical method, was applied for the analysis of flavonoids, coumarins and chlorogenic acid in the fruit, bark and leaves of white mulberry from China from which camepferol, rutin, chlorogenic and gallic acid were isolated [13]. This analytical method was also used to isolate routines, quercetin, catechins, chlorogenic, caffeic, gallic, vanillinic acid and $\mathrm{m}$ - and o-coumaric acids from black, red and white mulberry extracts from Turkey [14]. Quercetin and rutin were also isolated from white, red and black mulberry from China [15].

White and black mulberries from Serbia contain rutin, quercetin and phenolic acids: gallic, caffeic, chlorogenic, vanillin, ferulic, dihydroxybenzoic and p-coumaric acid [16]. Chlorogenic, $p$ - and m-coumaric, vanillin, gallic and ferulic acids were isolated from the fruits and leaves of white and black mulberry from Pakistan [19].

\section{CONCLUSION}

In the extracts of white, red and black mulberry identified the four phenolic acids by HPLC analysis: chlorogenic, 4-caffeoylquinic, 5-caffeoylquinic and caffeic acid. 5-caffeoylquinic acid was identified in all tested extracts of white, red and black mulberry. 4-caffeoylquinic acids contain all the extracts except methanol extract of red mulberry. Caffeic and chlorogenic acid containing methanol extracts of white and red mulberry.

In the tested extracts, the following flavonoids were confirmed by HPLC analysis: quercetin-3-O-rutinoside, quercetin-3-O-glucoside, quercetin-3-Oramnoside, kaempherol-3-O-rutinoside and quercetin. All of the three tested 
species of mulberry extracts containing quercetin-3-O-rutinoside and quercetin3-O-glucoside. Quercetin-3-O-ramnoside containing all tested extracts except methanol extract of white and red mulberry. Quercetin contains only the methanol extract of black mulberry.

The methanolic extract of black mulberry contains the following anthocyanins: cyanidin-3-O-glucoside, cyanidin-3-O-rutinoside, pelargonidin-3O-glucoside and pelargonidin-3-O-rutinoside. The acetone extract of black mulberry contains all of these anthocyanins except pelargonidin-3-O-glucoside. The methanolic extract of red mulberry contains cyanidin-3-O-glucoside. In the extracts of white mulberry anthocyanins have not been identified.

\section{EXPERIMENTAL}

Preparation of materials: Plant material was collected in the South East Serbia in early July 2011. Fresh fruit maturity was estimated on the basis of the color. Samples were stored in plastic bags and kept frozen until extraction. The frozen fresh fruit material homogenized using a blender. Black, red and white mulberry fresh fruits $(10 \mathrm{~g})$ was extracted with water, methanol-water $(50 / 50, v / v \%)$, methanol, ethanol-water $(50 / 50, v / v \%)$, ethanol, acetone-water $(50 / 50, v / v \%)$ and acetone. All solvents were acidified with $1 \mathrm{ml}$ conc. $\mathrm{HCl}$. The extraction was performed with $100 \mathrm{ml}$ of solvents using the ultrasonic bath for 30 minutes. The suspension was gravity filtered through a Buchner funnel and Whatman No. 1 filter paper. Extracts were stored in the fridge at $5^{\circ} \mathrm{C}$ until their analysis.

High-performance liquid chromtagraphy (HPLC) analysis: High performance Liquid Chromatography (HPLC) liquid chromatography with UV I Vis and a high resolution fluorescence detector (HPLC) was applied to separate and quantify the phenolic compounds in the prepared samples. The HPLC method was developed, with the following parameters showing the best results. Chromatographic separation was performed on an Eclipse XDB-C18 column $(4.6 \mathrm{~mm} \times 150 \mathrm{~mm})$ using a solvent system: $\mathrm{A}-(\mathrm{H} 2 \mathrm{O}+5 \% \mathrm{HCOOH})$ and $\mathrm{B}-(80 \% \mathrm{ACN}+5 \% \mathrm{HCOOH}+\mathrm{H} 2 \mathrm{O})$.

Separation of components was performed using the following linear gradient: 0-28 min, 0.0\% B; 28-35 min, 25\% B; 35-40 min, 50\% B; $40-45 \mathrm{~min}$, $80 \% \mathrm{~B}$, and finally $0 \% \mathrm{~B}$ again for the last $10 \mathrm{~min}$. The mobile phase flow was $0.8 \mathrm{~cm}^{3} / \min .5 \mu \mathrm{l}$ of sample solution was injected automatically using autosamplers. The column was thermostatically controlled at $30^{\circ} \mathrm{C}$. 
DANICA DIMITRIJEVIĆ, DANIJELA KOSTIĆ, MILAN MITIĆ, DUŠAN PAUNOVIĆ, BRANKA STOJANOVIĆ, JOVANA KRSTIĆ, SLAVICA STEVANOVIĆ, JASMINA VELIČKOVIĆ

The phenolic components present in the samples were identified by comparing their retention times and spectra with the retention time and spectrum of standards for each component. The following standards were used: malvidin-3-glucoside, cyanidin-3-glucoside, halogen acids, p-coumaric, caffeic and ferulic acids, catechin, epicatechin, quercetin and caempherol. The quantitative determination of the components was performed by the external standard method.

For each individual standard, a stock solution of a mass concentration standard of $1.0 \mathrm{mg} / \mathrm{cm}^{3}$ was prepared by dissolving in $10 \%$ methanol solution. A calibration curve, for each standard, was constructed based on the obtained surfaces, depending on the mass concentration of the standard. From the obtained linear dependence equation, mass concentrations of the components in the samples were calculated. For components in samples for which no standard was available, quantification was performed based on a calibration curve, by the structure of the corresponding standard. All analyzes were performed in triplicate.

\section{REFERENCES}

1. E.A. Cieslik; A.W. Grada; W. Adamus; Food Chem., 2006, 94, 135-142.

2. A. Sass-Kiss; J.P. Kiss; M.M. Milotay; M. Kerek; M. Toth-Markus; Food Res. Inter., 2005, 38, 1023-1029.

3. L.K. Liu; F.P. Chou; Y.C. Chen; C.S. Chyan; J Agric Food Chem., 2009, 57. 76057611.

4. A. Trappey; H. Bawadi; R.R. Bansode; N.J. Losso; Food Chem., 2005, 91, 665-672.

5. J.Y. Lin; C.Y. Tang; Food Chem., 2007, 101, 140-147.

6. M. Ozgen; S. Serce; K. Kaya; Sci. Hortic., 2009, 119, 275-279.

7. S. Ercisli; E. Orhan; Sci. Hortic., 2008, 116, 41-46.

8. Q. Du; J. Zheng; Y. Xu; J. Food Compos. Anal., 2008, 21, 390-395.

9. M.R. Perez-Gregorio; J. Reguiero; E. Alonso-Gonzales; L.M. Pastrana-Castro; J. Simal-Gandara; LWT, 2011, 40, 1793-1801.

10. A.M. Pawlowska; W. Oleszek; A. Braca; J. Agric. Food Chem., 2008, 56, 33773380.

11. N.M.A. Hassimotto; M.I. Genovese; F.M. Lajolo; Food Sci.Technol. Int., 2007, $13,17-25$.

12. I. Thabti; W. Elfalleh; H. Hannachi; A. Ferchichi; M. Da Graca Campos; J. Funct. Foods, 2012, 4, 367-374.

13. Q. Chu; M. Lin; H. Tian; J. Ye; J. Chromatogr. A, 2006, 1116, 286-290.

14. M. Gundogdu; F. Muradoglu; R.I. Gazioglu Sensoy; H. Yilmaz; Sci. Hortic.,2011, $132,37-41$. 

MORUS SPECIES FROM SOUTHEAST SERBIA

15. M. Isabelle; B. Lan Lee; C. Nam Ong, X. Liu; D. Huang; J. Agric. Food Chem., 2008, 56, 9410-9416.

16. M.M. Radojković; Z.P. Zeković; S.S. Vidović; D.D. Kocar; P.Z. Masković; Hem. Ind., 2012, 66, 547-552.

17. O. Mazimba; R.R.T. Majinda; D. Motlhanka; Afr. J. Pharm. Pharmacol., 2011, 5, 751-754.

18. O. Ercsli; E. Orhan; Sci. Hortic., 2008, 116, 41-46.

19. A.A. Memon; N. Memon; L.D. Luthria; I.M. Bhanger; A.A. Pitafi; Pol. J. Food Nutr. Sci., 2010, 60, 25-32. 